\title{
REDUKSI ATRIBUT BERDASAR MATRIK DISCERNIBILITY TEORI ROUGH SET DALAM SIMULASI BENCANA KEBAKARAN
}

\author{
Hendrik Fery Herdiyatmoko \\ Fakultas Sains dan Teknologi, Program Studi Sistem Informasi \\ Universitas Musi Charitas Palembang \\ Email: hendrik_023@yahoo.co.id
}

\begin{abstract}
ABSTRAK
Bencana kebakaran dapat terjadi dimana saja dan kapan saja, dapat terjadi di area tempat tinggal, di tambang dan di . Terdapat isu penting pada deteksi kebakaran otomatis, yaitu mengenai data parameter kebakaran. Parameter kebakaran ini dapat berupa suhu, kelembaban, bahan bakar kebakaran, titik api, dll. Dalampenelitianini data parameter kebakaran dikumpulkanolehjaringanwirelesssensor networkyang diposisikansecaraspesifikpadalokasi di dalam gedung. Namun, tidak semua parameter kebakaran akan digunakan, karena semakin banyak parameter kebakaran digunakan akan menyebabkan beban komputasi bertambah, sehingga data parameteryang paling penting saja yang akan digunakan. Salah satu cara mengekstraksi komponen yang paling penting adalah menggunakan seleksi parameter kebakaran berbasis reduksi atributdenganteknikTeori Roughset.Tujuan dari penelitian ini adalah mereduksi parameter atau atribut kebakaran yang menghasilkan kompleksitas yang lebih rendah pada analisis data kebakaran. Hasilkeluaran reduksiatributtersebut digunakan sebagai dasar pencarian jalur evakuasi bencana kebakaran.
\end{abstract}

Kata kunci: teori rough set, reduksi atribut,wireless sensor network.

\section{ABSTRACT}

Fire disaster can occur anywhere, anytime, can occur in the area of residence, in mines and in the woods. There is an important issue in the automatic fire detection, which on fire parameter data. Parameters of these fires can be temperature, humidity, fuel fires, fires, etc. In this study fires parameter data collected by the sensor network wireless networks are positioned specifically on the location in the building. However, not all parameters of fires will be used, because the more parameters used fires will cause computational load increases, so the data is the most important parameters that will be used. One way to extract the most important component is the use of parameter selection attribute based on attribute reduction with Rough Set Theory. The purpose of this study is to reduce the parameters or attributes of fires that produce lower complexity in the data analysis of fires. The output of attribute reduction is used as the basis for an evacuation route search catastrophic fires.

Keywords: rough set theory, dijkstra algorithm, wireless sensor network.

\section{PENDAHULUAN}

Dari ratusan data sistem, atribut dan data sampel bias sangat besar, dengan setiap atribut memiliki fungsi yang berbeda - beda, dan banyak atribut berpotensi besar terjadi redudansi. Salah satu cara untuk mengurangi redudansi adalah dengan reduksi atribut. Reduksi atribut dapat mengeliminasi atribut redundant dari data system dan menjaga klasifikasi tetap atau tidak berubah - ubah.

Penelitian ini menggunakan Teori Rough Set (RS) dalam reduksi parameter kebakaran pada sebuah gedung. Parameter tersebut diantaranya FFMI, ISI, temperatur dan kelembaban relatif [1]. Tabel reduksi diambil dari simulasi data yang dikumpulkan oleh wireless sensor network yang dipasang pada posisi spesifik di dalam sebuah gedung bertingkat. Reduksi dilakukan dengan mengekstraksi parameterparameter kebakaran terpilih guna mengurangi beban komputasi. Proses ekstraksi yaitu menyeleksi (reducing) parameter yang dianggap memiliki kemiripan. Hal ini dapat dilakukan dengan menggunakan teori RS berbasis discernibility matrixyang bertujuan menghasilkan tabel keputusan baru berisikan parameter terpilih yang nantinya akan digunakan dalam menentukan titik awal jalur evakuasi. 


\section{METODE PENELITIAN}

\subsection{Analisis Data Riil Dengan Data Simulasi}

Penelitian ini menggunakan data simulasi yang merepresentasikan data riil di lapangan. Untuk indikator kebakaran dalam area tempat tinggal biasanya diklasifikasikan menjadi unit nyala api, bara api, dan cepat-lambat bara api [2]. Sedangkan parameter penyebab kebakaran adalah tingkat kerapatan/kepekatan asap, kadar $\mathrm{CO}$, dan temperatur.

\subsection{Teori Rough Set}

Teori Rough set dipolerkan oleh Zdzislaw Pawlak pada tahun 1982 [3], teori ini merupakan metodologi yang berfokus pada klasifikasi dan analisis imprecise / ketidaktepatan, uncertain / ketidakpastian atau informasi dan pengetahuan tidak lengkap. Konsep dasar dari teori Rough set adalah approximation of lower dan upper space of set.

Dalam penelitian yang dilakukan oleh Majid Bahrepour, Nirvana Meratnia, Paul Havinga[4] yang melakukan penelitian tentang human resources development menggunakan pendekatan rough set, memberikan hasil penelitian dengan membuatsistem pengambil keputusan untuk memandu organisasi dalam menentukan strategi terhadap human resource management dan customer relationship management.

Reduksi pada teori Rough set dapat dilakukan salah satu diantaranya dengan menggunakan metode Characteristic Of Consictent Approximation Space (CAS) yang dipresentasikan untuk memberi sinyal alarm kebakaran dari beberapa sensor kebakaran yang berbeda, menggunakan decision rule yang diperoleh dari data sampel dalam CAS dengan fasilitas klasifikasi data [5].

\subsubsection{Information System}

Secara umum, sistem informasi dinotasikan sebagai IS, didefinisikan sebagai IS $=(U, A, V, f)$, dimana $U$ merupakan objek Universal dan $A$ merupakan himpunan terbatas dari atribut $\{a 1, a 2, a 3, \ldots . .$, $\left.a_{n}\right\}$. Setiap atribut a anggota dari himpunan $\mathrm{A}$, sehingga a $\boldsymbol{\epsilon} \mathrm{A} . \mathrm{f}_{\mathrm{a}}: \mathrm{U} \rightarrow \mathrm{V}_{\mathrm{a}}$, dimana $\mathrm{V}_{\mathrm{a}}$ merupakan himpunan dari nilai atribut, yang dinamakan domain dari atribut a.

\subsubsection{Lower dan Upper Approximation}

Misal $\mathrm{X}$ adalah himpunan bagian dari elemen dari universe $U$, sehingga $X \subseteq U$. Maka dapat dikatakan himpunan bagian $P$ dalam $V_{a}$, sehingga $P \subseteq V_{a}$. Low Approximation dari $\mathrm{P}$, ditulis sebagai $\underline{P X}$, dapat didefinisikan oleh union dari semua elemen himpunan $x_{i}$ yang terkandung dalam $\mathrm{X}$ dengan persamaan sebagai berikut :

$\underline{\mathrm{PX}}=\left\{x_{i} \in U \mid\left[x_{i}\right]\right.$ ind $\left.(\mathrm{p}) \subseteq X\right\}$

Dimana $x_{i}$ himpunanutama yang tergantungdalam $\mathrm{X}, i=1,2, \ldots \ldots, n$.

Uppper approximationdari $\mathrm{P}$, dinotasikansebagai $\mathrm{PX}$ yang dapat didefinisikan sebagai irisan tidak kosong dari semua elemen himpunan $x_{i}$ yang terkandung dalam $\mathrm{X}$, dengan persamaan sebagai berikut:

$\overline{P X}=\left\{x_{i} \in U \mid\left[x_{i}\right]_{\operatorname{md}(\mathrm{p})} \cap X \neq \not\right\}$

Boundarydari X dalam U didefinisikansebagai:

$P N X=P X-\underline{P X}$

Tabel 1 menampilkan konseptual dari Lower dan Upper Approximation.

Tabel 1. KonsepUpper dan Lower Approximation

\begin{tabular}{lccc}
\hline \multicolumn{1}{c}{ Objeck/attribute } & a1 & a2 & $\boldsymbol{a 3}$ \\
\hline object1, object3\} & 3 & 1 & 3 \\
object 2, object 4, onject 9$\}$ & 1 & 2 & 3 \\
\{bject5, object7\} & 2 & 2 & 4 \\
\{object6, object 8 \} & 1 & 2 & 2 \\
\hline
\end{tabular}


PenjelasanTabel 1:

Terdapat Sembilan objek dari himpunan X.

$X=\{$ object1, object 2 , object 3 , object 4 , object5, object6, object7, object8, object 9$\}$.

Elemen dasar dari himpunan yang terkandung dalam $X$ adalah \{object1, object 3$\}$, \{objeck2, object 4 , object9\}. Sehingga Lower Upproximation-nya adalah:

$\underline{\mathrm{PX}}=\left\{x_{i} \in U \mid\left[x_{i}\right]\right.$ ind $\left.(\mathrm{p}) \subseteq X\right\}$ persamaan (1)

$\underline{\mathrm{PX}}=\{$ object 1, object 3 object 2 , object 4 , object 9$\}$

Untuk menghitung Upper Approximation dari himpunan bagian X, setidaknya terdapat satu elemen dari subset X, yaitu: Object1, object3 object2, object4, object9 object5, object7. Sehingga Upper Approximation adalah:

$\underline{P X}=\left\{x_{i} \in U \mid\left[x_{i}\right]_{\mathrm{md}(\mathrm{p})} \cap X \neq \emptyset\right\}$ persamaan (2)

$\mathrm{PX}=\{$ object1, object3, object2, object4, object9, object5, object7 $\}$

Dan Boundary dari $X$ dalam $U$ dengan menggunakan persamaan (3) adalah:

PNX $=\{$ object1, object 3 , object 2, object 4, object 9, object5, object 7$\}-\{$ object1,object 3, object 2 , object4, object9\}

$=\{$ object5, object 7$\}$

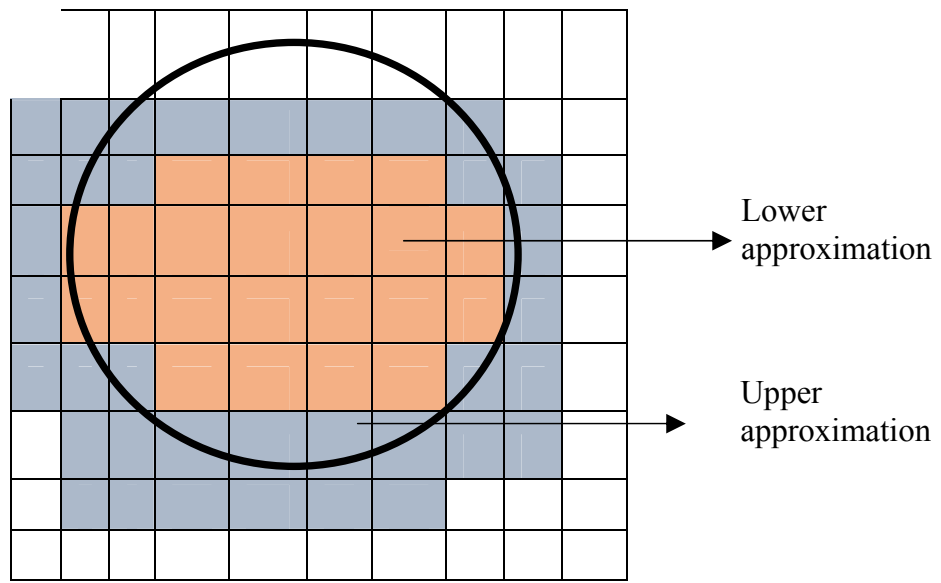

Gambar 1. Lower dan Upper Approximation

\subsubsection{Core dan reduksi atribut}

1) Reduksi

Dimensi natural dari pereduksian suatu data diidentifikasikan dengan kelas-kelas ekivalensi, misalnya mereduksi objek-objek indiscernible (tidak dapat dipisahkan) menggunakan atribut-atribut yang tersedia. Pengguanaan atribut-atribut tersebut dapat dilakukan selama elemen kelas ekivalensi tersebut dibutuhkan dalam merepresentasikan seluruh kelas. Dimensi lain dalam pereduksian adalah menyimpan atribut-atribut yang memiliki sifat mempertahankan relasi indiscernibility dan karenanya diperlukan pendekatan himpunan. Atribut-atribut yang berada dalam daerah penolakan dianggap berlebih karena penghapusan atribut-atribut tersebut tidak akan memperburuk klasifikasi. umumnya, akan ada subset atribut-atribut tersebut dan himpunan yang minimal itu disebut reducts.

2) Core

Konsep Core secara umum digunakan dalam semua reduksi. Reduksi atribut dapat menghapus atribut berlebihan dan memberikan keputusan informasi yang simpel atau lebih sederhana.Core $\mathrm{C}$ didefinisikan sebagai himpunan dari atribut yang menjadi milik irisan dari semua reduksi $\mathrm{C}$.

$\mathrm{COR}(\mathrm{C})=\cap_{\mathrm{B}} \boldsymbol{\epsilon}_{\mathrm{RED}(\mathrm{C})} \mathrm{B}$

Sebagaicontoh,misal $\mathrm{C}=\{$ temp, blood-p, EKG, cholesterol $\}$ danreduksidari $\mathrm{C}$ yaitu \{temp, blood-p, EKG $\}$ dan \{blood-p, EKG, cholesterol $\}$. Sehingga CORE $(C)=\{$ blood-p, EKG $\}$

3) Matrik Discernibility dan Function

Discernibility Function $f_{s}$ untuk sebuah system infomasi S adalah sebuah fungsi Boolean dari $m$ Boolean variables $a_{1} \ldots . a_{m}$ yang didefinisikan sebagai:

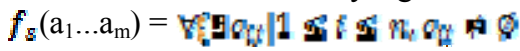

$\operatorname{Dimana} c_{i j}=\left\{\boldsymbol{a}^{9} \mid \boldsymbol{\alpha} \mathbf{a} \boldsymbol{\theta}_{\mathrm{ij}}\right\}$.

Misalkan fungsi discernibility untuk suatu table adalah T (H V M) (HV MV T) (MV T). Setelah disederhanakan dengan fungsi discernibility menggunakan aturan absorbs diperoleh hasil TH V TM. 
Metode reduksi pada penelitian ini menggunakan metode Matrik Discernibility [3,12]. Secara sederhana, langkah-langkah reduksi dengan Matrik discernibility adalah:

1) Inisiasi table reduksi yaitu memberikan nilai terhadap table reduksi berupa nilai random dengan nilai rentangan random disesuaikan dengan banyak atribut yang terbentuk. Nilai tersebut mempresentasikan nilai untuk setiap node sesuai dengan parameter masing-masing.

2) Melakukan proses Indiscernibility yang bertujuan membandingkan nilais etiap parameter suatu node dengan nilai pada setiap node lainnya guna memperoleh hasil yang Disecernibility (dapat dibedakan). Proses ini mencapai pertidaksamaan antara dua objek yang dibandingkan.

3) Melakukan proses reduksi dengan aljabar Boolean. Proses ini melibatkan dua hokum aljabar Boolean, seperti absorbsi (penyerapan) dan distributif. Hasilnya berupa parameter akhir yang akan dilibatkan dalam proses penentuan wireless sensor network dengan indikasi kebakaran tertinggi.

\subsection{Wireless Sensor Network}

Wireless sensor network dapat mendeteksi dan meramalkan kebakaran lebih cepat dari pendekatan deteksi berbasis satelit. Data indikasi kebakaran dikumpulkan dan diproses untuk mendeteksi kebakaran secara real time [6,7]. Dengan menghubungkan data kebakaran yang dikumpulkan oleh wireless sensor network dan data yang uncertainly dapat dicari solusi menggunakan metode rough set dimana sumber data dibatasi oleh lingkungan [7].

Dalam penelitian yang dilakukan oleh Shaohua Chenet al. [8] yang melakukan survei dari beberapa studi mengenai wireless sensor network (WSN) yang berasal dari tiga perspektif, teknik deteksi kebakaran untuk area tempat tinggal, teknik deteksi kebakaran untuk hutan dan kontribusi sensor network untuk deteksi dini kebakaran.

Teknologi deteksi kebakaran tradisional biasanya menggunakan single unit fire detector termasuk metode ambang batas dan metode analog kebakaran. Single unit fire detector memprediksi kebakaran dengan hanya mendeteksi satu parameter spot kebakaran. Kelemahan metode ini yaitu tidak ada satu jenis unit detektor tunggal kebakaran dapat mendeteksi jenis kebakaran secara efektif. Kesalahan deteksi dan delay peringatan kebakaran sering terjadi. Metode baru deteksi kebakaran adalah dengan metode multisensor data fusion dengan menggunakan pendekatan sinkronisasi dan integrasi multi-sensor data fusion.

Untuk parameter kebakaran, menurutShaohua Chenet al. [8] yang melakukan survei terhadap parameter kebakaran dari berbagai sistem monitoring, diantaranya Fire Weater Index (FWI), National Fire Danger Rating System (NFDRS). Parameter kebaran menurut FWI terdapat 4 indikator yaitu temperatur, kelembaban relatif, angin dan hujan. Sedangkan menurut NFDRS indikasi kebakaran diklasifikasikan berdasar tingkat indeks, yaitu Occurence Index, Burning Index, Fire Load Index.

Pada penelitian ini parameter kebakaran merujuk pada data FWI (Canadian Fire Index) [9]. Data disesuaikan dengan kondisi penelitian yaitu parameter kebakaran di dalam gedung, dengan parameter sebaga iberikut:

1) Parameter utama yaitu temperature (temp), relative humidity $(\mathrm{RH})$.

2) Untuk parameter yang berpotensi menimbulkan kebakaran di dalam gedung meliputi FFMC (Fine Fuel Moisture Code) yaitu berisi parameter kadar air, ISI (initial spread index) berisi parameter kecepatan rambat api.

\subsection{Model Bangunan}

Model bangunan diasumsikan pada suatu lingkungan tertentu pada suatu lantai bertingkat, terdapat ruangan dan orang. Diasumsikan ruangan ada pada lantai 2 dengan satu anak tangga. Model bangunan dapat dilihat pada Gambar 2. 


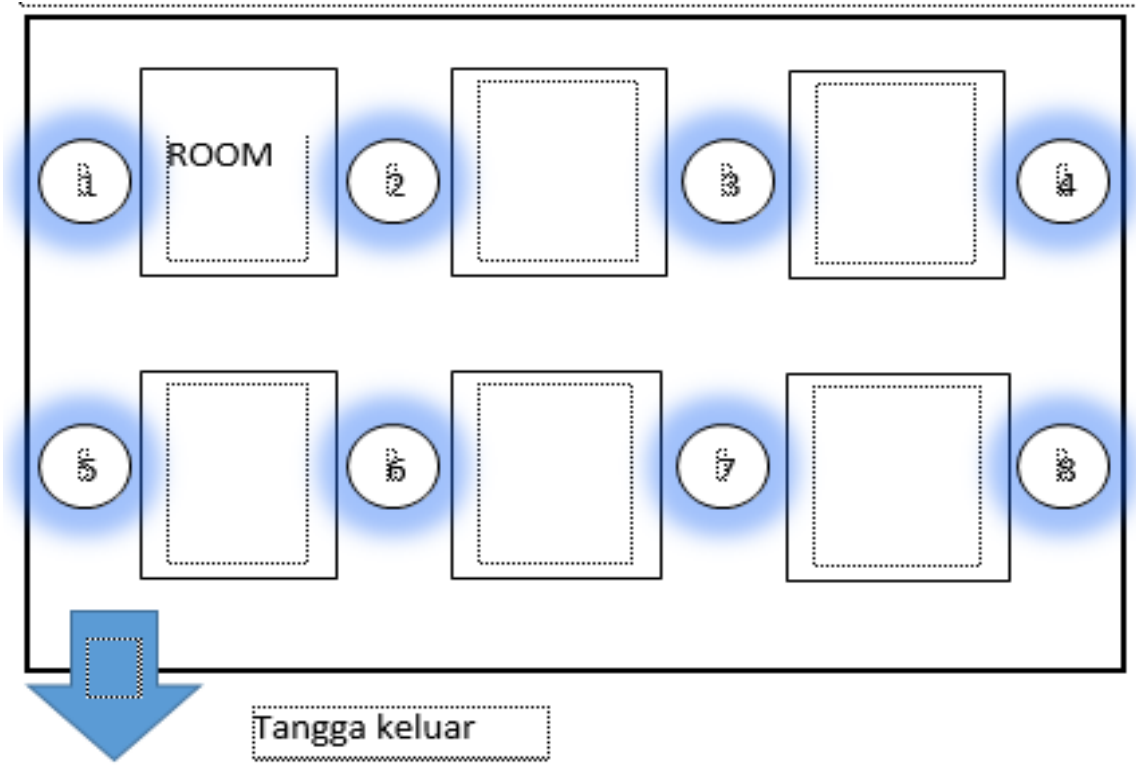

Gambar 2. Simulasi Model Bangunan

Keterangan Gambar 2:

: node $(8$ node $)$

: ruangan

\section{HASIL DAN PEMBAHASAN}

Dalam analisis, data IS diproses menggunakan aplikasi Reduct Discern berbasis C Sharp [10]. Gambar 3 adalah aplikasi Reduct Discern dengan tabel IS dan hasil reduksi.

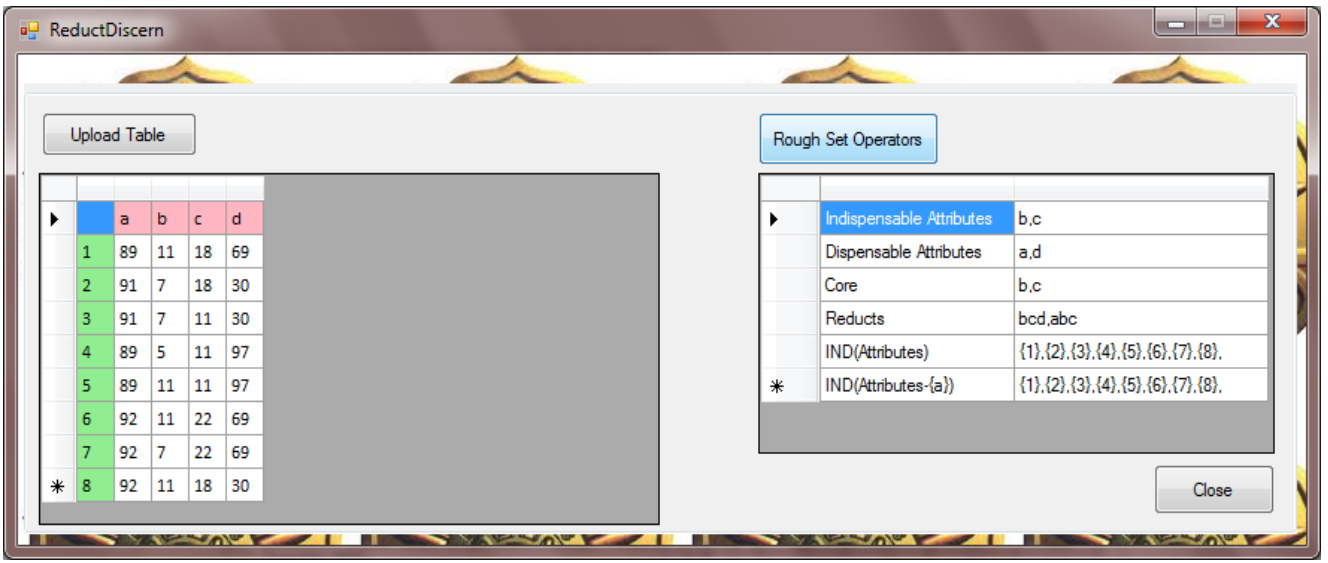

Gambar 3. Aplikasi Reduct Discern dengan Hasil Reduksi

Data indikator kebakaran diambil dari 8 node WSN yang terpasang pada tempat atau area yang spesifik (Gambar 2). Empat parameter kebakaran yaitu FFMC, ISI, temp, RH akan membentuk tabel reduksi dengan atribut berupa parameter - parameter kebakaran.

Untuk mencari hasil reduksi dengan metode Discernibility matrix of Rough Set theory, digunakan contoh data riil dari wireless sensor network. Standar tes data diambil dari data FWI [11]. Tabel 2 merupakan contoh dari Information System. 
Tabel 2. Sistem informasi sensor kebakaran

\begin{tabular}{ccccc}
\hline Node & $\boldsymbol{F F M C}$ & $\boldsymbol{I S I}$ & $\boldsymbol{T e m p}$ & $\boldsymbol{R H}$ \\
\hline 1 & 89 & 11 & 18 & 69 \\
2 & 91 & 7 & 18 & 30 \\
3 & 91 & 7 & 11 & 30 \\
4 & 89 & 7 & 11 & 97 \\
5 & 89 & 11 & 11 & 97 \\
6 & 92 & 11 & 22 & 69 \\
7 & 92 & 7 & 22 & 69 \\
8 & 92 & 11 & 18 & 30 \\
\hline
\end{tabular}

Fungsi information system dari Tabel 2 adalah:

$U=\{1,2,3,4,5,6,7,8\}$

$A=\{$ FFMC, ISI, temp, RH $\}$

$F F M C=\{89,91,92\}$

$I S I=\{7,11\}$

temp $=\{11,18,22\}$

$R H=\{30,69,97\}$ matrix.

Dengan menggunakan Tabel 2 sebagai Tabel informasi, diperoleh Tabel 3 sebagai hasil discernibility

Tabel 3. Hasil discernibility matrix dari tabel IS

\begin{tabular}{|c|c|c|c|c|c|c|c|c|}
\hline & p1 & $p 2$ & p3 & p4 & p5 & p6 & $p 7$ & $p 8$ \\
\hline $\mathrm{p} 1$ & $\begin{array}{c}\text { FFMC, ISI, } \\
\text { RH }\end{array}$ & - & - & - & - & & & \\
\hline $\mathrm{p} 2$ & $\begin{array}{c}\text { FFMC, ISI, } \\
\text { RH }\end{array}$ & - & - & - & - & & & \\
\hline p3 & $\begin{array}{c}\text { FFMC, ISI, } \\
\text { Temp, RH }\end{array}$ & Temp & - & - & - & & & \\
\hline $\mathrm{p} 4$ & ISI, RH & ISI, Temp, RH & FFMC, RH & - & - & & & \\
\hline p5 & Temp, RH & Temp, RH & $\begin{array}{l}\text { FFMC, } \\
\text { ISI, RH }\end{array}$ & ISI & - & & & \\
\hline p6 & $\begin{array}{c}\text { FFMC, } \\
\text { Temp }\end{array}$ & FFMC, Temp & $\begin{array}{l}\text { FFMC, } \\
\text { ISI, Temp, } \\
\text { RH }\end{array}$ & $\begin{array}{l}\text { FFMC, } \\
\text { ISI, Temp, } \\
\text { RH }\end{array}$ & $\begin{array}{c}\text { FFMC, } \\
\text { Temp, } \\
\text { RH }\end{array}$ & & & \\
\hline $\mathrm{p} 7$ & $\begin{array}{c}\text { FFMC, ISI, } \\
\text { Temp }\end{array}$ & $\begin{array}{c}\text { FFMC, Temp, } \\
\text { RH }\end{array}$ & $\begin{array}{c}\text { FFMC, } \\
\text { Temp, RH }\end{array}$ & $\begin{array}{l}\text { FFMC, } \\
\text { Temp, RH }\end{array}$ & $\begin{array}{c}\text { FFMC, } \\
\text { ISI, } \\
\text { Temp, } \\
\text { RH }\end{array}$ & ISI & & \\
\hline p8 & FFMC, RH & FFMC, ISI & $\begin{array}{l}\text { FFMC, } \\
\text { ISI, Temp }\end{array}$ & $\begin{array}{l}\text { FFMC, } \\
\text { Temp, RH }\end{array}$ & $\begin{array}{c}\text { FFMC, } \\
\text { Temp, } \\
\text { RH }\end{array}$ & $\begin{array}{l}\text { Temp } \\
\text {, RH }\end{array}$ & $\begin{array}{c}\text { ISI, } \\
\text { Temp } \\
\text {, RH }\end{array}$ & \\
\hline
\end{tabular}

Pada Tabel 3 di atas, untuk $F, I, T, R$ yang masing - masing merepresentasikan FFMI, ISI, temp, RH, sehingga fungsi discernibility dari Tabel 3 adalah $f_{s}(F, I, T, R)=$

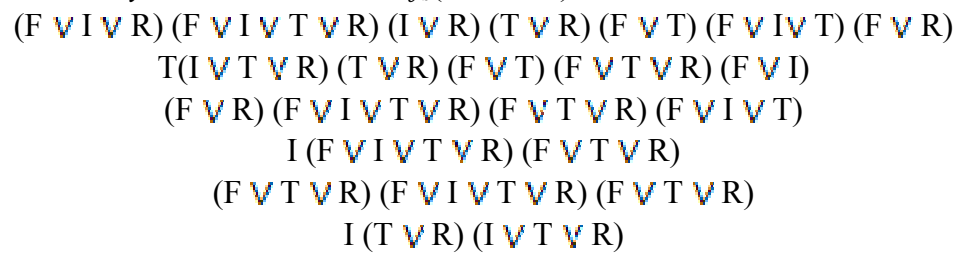


Dimana $\vee$ adalah notasi disjungsi dan konjungsi yang digunakan sebagai formula. Setiap baris dari fungsi discernibility berhubungan dengan satu kolom dalam tabel discernibility matrix. Matrik tersebut simetris dengan diagonal kosong. Data berututan dalam kurung merupakan sebuah konjungsi dari fungsi Boolean. Setelah penyederhanaan, fungsi discernibility yang menggunakan aturan Algoritma Boolean memberikan hasil: (FFMI, Temp, RH), (FFMI, ISI, Temp)

Jika dipilih salah satu hasil reduksi, yaitu (FFMI, Temp, RH), maka node dengan informasi indikasi potensi kebakaran tertinggi adalah node 5. Pada Tabel 4 ditampilkan hasil reduksi dengan metode discernibility matrix memberi hasil sama dengan atribut tanpa reduksi.

Tabel 4. Hasil reduksi dengan discernibility matrix

\begin{tabular}{ccccccc}
\hline Node & FFMC & ISI & Temp & $\boldsymbol{R H}$ & $\begin{array}{c}\text { Tanpa } \\
\text { Reduksi }\end{array}$ & $\begin{array}{c}\text { Dengan } \\
\text { Reduksi }\end{array}$ \\
\hline 1 & 89 & 11 & 18 & 69 & 187 & 98 \\
2 & 91 & 7 & 18 & 30 & 145 & 55 \\
3 & 91 & 7 & 11 & 30 & 138 & 48 \\
4 & 89 & 7 & 11 & 97 & 204 & 115 \\
5 & 89 & 11 & 11 & 97 & 209 & 119 \\
6 & 92 & 11 & 22 & 69 & 195 & 102 \\
7 & 92 & 7 & 22 & 69 & 190 & 98 \\
8 & 92 & 11 & 18 & 30 & 150 & 59 \\
\hline
\end{tabular}

\section{KESIMPULAN}

Teori Rough Set dapat memisahkan faktor penting dari atribut kebakaran dengan aturan Boolean yang merupakan bagian dari proses reduksi dengan discernibility matrix yang ada di dalamnya. Reduksi yang dihasilkan memberikan atribut reduksi sebagai informasi untuk deteksi dini kebakaran di dalam sebuah gedung bertingkat yang disebarkan melalui wireless sensor network.

\section{SARAN}

Algoritma reduksi yang digunakan dalam penelitian ini hanya mampu untuk tabel keputusan yang konsisten, untuk penelitian selanjutnya dapat mengunakan data dengan tabel keputusan yang dapat berubah-ubah.

\section{DAFTAR PUSTAKA}

[1] Liyang Yu, Neng Wang,Xiaoqiao Meng, 1995, Real-time Forest Fire Detection with Wireless Sensor Networks.Proceedings of 13th International Conference on Computer and Information Tecnology, Shanghai, China, vol 2, 1214- 1217.

[2] Sanchita Mal-Sarkar, Ifthikhar U. Sikder, Vijay K. Konangi, 2010, Application of Wireless Sensor Networks in Forest Fire Detection under Uncertainly, 13th International Conference on Computer and Information Technology (ICCIT), Cleveland, USA, pages 193-197.

[3] Zdzislaw Pawlak, 1982, Rough Set, International Journal of Information and Computer Sciences.

[4] Majid Bahrepour, Nirvana Meratnia, Paul Havinga, 2008, “Automatic Fire Detection: A Survey From Wireless Sensor Network Perspective”, Pervasive System Group, Univeristy of Twente.

[5] Shinya Imai, Che-Wei lin, Junzo Watada, Gwo-Hishiung Tzeng, 2008, "Rough Set Apptoch to Human Resources Development of Information Technology Corporation”, Waseda, Japan, vol 9, 2.

[6] Liyang Yu, Neng Wang, Xiaoqiao Meng, 2005, "Real-time Forest Fire Detection with Wireless Sensor Networks", Proceedings of Wireless ommunications, Networking and Mobile Computing, Vol 2, 1214 - 1217

[7] Naiwei Cheng, 2010, “A Decision-Making for Fire Detection Data Fusion Based on Rough Set Approach", International Conference on Intelligent System Design and Engineering Application (ISDEA), Vol 1, 8 -10.

[8] Shaohua Chen, Hong Bao, Xianyan Zeng, Yimin Yang, 2003, "Fire Detection Based on Multisensor Data Fusion", IEEE International Conference on Systems, Man and Cybernetics, Vol 4, 3775 -3780 . 
Jurnal SIMETRIS, Vol 8 No 1 April 2017

ISSN: 2252-4983

[9] Canadian Forest Fire Index (FWI). http://cwfis.cfs.nrcan.gc.ca/background/summary/fwi.

[10] MSDN C\# Tutorial. Microsoft Developer Pram. http://msdn.microsoft.com/enus/library/aa288436(v=vs.71).aspx 